International Journal of Child, Youth and Family Studies (2012) 2 \& 3: 125-127

\title{
INTRODUCTION TO THE SPECIAL CONFERENCE ISSUE
}

\section{Jennifer White and Veronica Pacini-Ketchabaw, Guest Editors}

This is the first special conference issue to be published by the International Journal of Child, Youth and Family Studies. It brings together keynote talks, a roundtable conversation, peer-reviewed conference papers as well as a book review. Most of the contributions included here were featured at the Child and Youth Care in Action III Conference, Leading Conversations in Research, Practice and Policy, which took place in Victoria, British Columbia, April 28 to 30, 2011. As the co-chairs of this conference, it gives us great pleasure to introduce this special conference edition of the IJCYFS.

We organized the conference to create a space for critically engaged conversations that would extend and challenge learning in our field. We thought that having these conversations was more pressing than ever given the unprecedented and wide-ranging demands we face in our work with children, youth, families, and communities. This conference attempted to engage with this complexity through such questions as:

- Can the current conceptual tools and language of child and youth care critically engage with the multiple and competing demands that practitioners, policymakers, and researchers encounter in their everyday work?

- What are the restrictions and exclusions of contemporary conversations in child and youth care?

- How can we open up the field of child and youth care so it does not limit our horizons and restrict our imaginations?

- How do we decide on the value and relevance of our work?

- What do we need to grasp the complexities we encounter in everyday practices?

- Can child and youth care embrace the intricacies of embodiment and our everyday relationships with the non-human world?

- What kinds of new languages and related practices can be mobilized in our work with children, families, and communities?

- How can we engage in a culture of critique in child and youth care and, simultaneously, work with children, youth, and families experiencing difficulties?

With these questions in mind, we opened possibilities for a wide range of themes to be explored at the conference, including:

- Child and youth care identities: professionalism and beyond

- The intricacies and complexities of practice

- Innovative approaches to working with children, youth, families, and communities 
International Journal of Child, Youth and Family Studies (2012) 2 \& 3: 125-127

- Critical, postmodern, feminist, queer approaches to working with children, youth, families, and communities

- Postcolonial, decolonizing, Indigenous approaches to working with children, youth, families, and communities

- Quantitative and qualitative approaches to child and youth care research

- Assessing quality in work with children, youth, and families

- Neo-liberal demands of everyday work with children, youth, families, and communities

- Perspectives on bodies and embodiment in work with children, youth, and families.

- Narrative approaches to child and youth care

- Pedagogical encounters

- Global perspectives in working with children, youth, families, and communities

- Community-level practices

These questions and themes inspired the articles in this journal issue.

As each of the contributions to this special issue attest, there are many overlapping conversations going on in the field of child and youth care (CYC) today. Collectively, they reveal a growing, dynamic, and contested field that is expanding in multiple directions. Several of the conference sessions raised important questions about the borders of CYC and the implications for a unified professional identity. Other sessions drew our attention to voices and perspectives that have largely been missing from the mainstream CYC literature, urging us to pay closer attention to the effects of our knowledge and practice frameworks. Drawing on multiple scholarly resources and intellectual traditions, several conference papers showcased the range of research, practice, and pedagogical innovations underway in CYC today.

We begin this issue with the roundtable discussion, Conversations on Conversing in Child and Youth Care, which features the voices of Sandrina de Finney, Kiaras Gharabaghi, J. N. Cole Little, and Hans Skott-Myhre in dialogue with each other. This piece is rather unconventional in that it attempts to retain the conversational and emergent quality that characterized the interactions these four authors had with one another during and following the conference roundtable. We think it provides a great example of how our differences can become creative sites of ongoing exploration.

Next we present the two keynote addresses delivered at our conference. The first is from Sibylle Artz, whose talk was intriguingly titled, Dis[s]curse[if] Challenges: Professional Conversations in Child and Youth Care in Fluid Modernity. In this highly stimulating keynote, Artz shared some of the stories of youth who participated in her research. The voices of youth were then set against the language of practice captured in official websites, newspaper stories, and media releases on the topic of youth crime and aggression. The second keynote session, Courageous Conversations in Child and Youth Care: Nothing Lost in the Telling, was delivered by Jin-Sun Yoon, who relied on the metaphor of the "elephant in the room" to directly confront the difficult issues of racism, homophobia, and colonialism in our field. The energetic and powerful response to her 
International Journal of Child, Youth and Family Studies (2012) 2 \& 3: 125-127

talk suggests that this might be an area where further exploration and dialogue could prove fruitful.

The conference papers are presented next, beginning with Daniel Scott's article in which he critically reflects on processes of CYC identity development and suggests that the field must avoid "a ghetto of exclusivity". Then, drawing on the work of Gilles Deleuze and Felix Guattari on bodies, Vanessa Clark eloquently theorizes her own art practice/research as political and ethical action. Next, Cait McMillan, Carol Stuart, and Jennifer Vincent describe the results of an innovative study that examined youth perceptions of CYC practitioners within an alternative school setting. Heather Sanrud and Patti Ranahan then describe a case study approach to preparing CYC practitioners that could be adapted for other higher education classroom settings.

Johanne Saraceno, like Yoon, then engages in unpacking the colonial routes/roots of professional child and youth care and, in turn, presents possibilities for socially just decolonizing praxis. Jeff Smith, also employing Deleuze and Guattari’s philosophy, presents examples of practice in which musical improvisation becomes a way of deterritorializing dominant understandings of therapeutic practice. Lynda Phillips and Ann Cameron follow, presenting their work which seeks to document the lived experience of childhoods without decontextualizing meaning using a range of tools and modalities. Kathleen Skott-Myhre challenges child and youth care to rethink the relational aspects of care. Drawing on feminist theory, she challenges us to de-centre humans as the primary player in a relation. Hans Skott-Myhre outlines further challenges to professional child and youth care by tracing the ways in which residential care can be conceptualized as a machinic social diagram that maps the relations of children and adults. In the last conference paper, Lara di Tomasso focuses critical attention on the treatment of migrant children in Canada based on a discursive analysis of a range of government, media, and public narratives and texts. The special issue concludes with Rebecca Raby's review of the book, Child and Youth Care: Critical Perspectives in Policy, Practice and Pedagogy, published by UBC Press in 2011.

We believe that this journal issue is about openings in CYC practice, research, and theory. It's about possibilities and new directions. The articles present many questions, at times re-articulating the field and at times reconfiguring the theme of the conference. The questions are not always new but they are always renewed. What is certain is that there is not a single story in the papers. The stories, though, are multilayered and always intertwined. We hope that the openings, possibilities, questions, and stories that emerge from this collection of articles provoke and move readers to reflect upon their own constructions, ethics, and politics of CYC. 